\title{
ABOUT A FEW FACTORS ASSOCIATED WITH THE GROWTH OF FRUIT IN SELECTING THE POLLINIZER FOR THE CHINESE PEAR
}

\author{
Akrra Kobayashi \\ (Hyogo Agricultural Experimental Station in Alashi City)
}

\section{Contents}

I. Introduction

II. Material and Methods

III. Rasults

1. Age of pistils in relation to set of fruit and its growth

2. Date of pollination in relation to growth of fruit

3. Variety of pollens in relation to set of fruit and its growth

IV. Discussion

The relation between the set-percentage in pollination and the growth of fruit

V. Conclusions and Summary

\section{Introduction}

In the fruit growing, the following are cited as the characteristics of the pollinizer; to be in a high compatibility with the main variety in orchard, to bloom in the same period as the main variety, to be a heavy producer of healthy pollens, and to bear fruit of market value.

Concerning this subject, the writer observed in 1936 about a few factors associated with the growth of fruit of the Chinese pear, such as i) the age of pistils, ii) date of pollination, iii) variety of pollens, and iv) setpereentage in pollination, considering the last most interesting.

However, this was a simple and inadequate experiment, only a preliminary one, requiring further and more extensive studies to determin which factor is the most important among them from the practical point of view. But, to his great regret the materials used for this purpose were rendered no longer available for a certain reason this winter and as it became impossible to continue the investigation, he has prepared this paper to recoid its results.

\section{Material and Methods}

1. Material: For this purpose, the pear trees planted in the orchard of $\mathrm{Hy}_{\mathrm{g}}=\mathrm{o}$ Agricultural Experimental Station in Akashi City were em- 
ployed. The names of the varieties, the ages of the trees, and the blossoming periods were as follows:

Table I--Material USed in this EXPeriment

\begin{tabular}{|c|c|c|c|c|}
\hline $\begin{array}{c}\text { Name of } \\
\text { variety }\end{array}$ & Age of tree & $\underset{\text { trees }}{\text { Number of }}$ & $\begin{array}{c}\text { Date of opening } \\
\text { of the first } \\
\text { blossom }\end{array}$ & $\begin{array}{l}\text { Date of full } \\
\text { blossoming }\end{array}$ \\
\hline Yari & $\begin{array}{c}8 \text { yea!s old } \\
\text { (Top-grafted) }\end{array}$ & 10 & April 19 & April 22 \\
\hline Tsuri & & 15 & 20 & 23 \\
\hline Imamuraaki & 15 years old & 5 & 21 & 24 \\
\hline Nijisseiki & 8 years old & 4 & 23 & 26 \\
\hline Yakumo & / & 5 & 24 & 28 \\
\hline Kikusui & " & 10 & 25 & 28 \\
\hline
\end{tabular}

2. Methods: About three days before blossoming, all the flower buds in each cluster except the three that seemed to have simultaneously developed, were removed, leaving in effect, roughly speaking, the 2nd, 3rd and 4 th ones accounted from below. Then the remainders were emasculated one day before blossoming, and soon after it each cluster of them was covered with a bag of paraffin paper. On the other hrnd, each cluster of the pollinizer which seemed to blossom the following day was also bagged on the evening of the day before pollination.

In pollinating, care was taken not to use the pollens which were left in a bag more than one day after the breaking-up of the anther. For, by bagging several young leaves at the basal part of a cluster were unavoidably covered together with flower buds, and if the bagged duration before pollination continues too long, especially at high temperature in daytime, the moisture content in the bag would become so high by the transpiration from the leaves that the germinating power of the pollens would be harmed. The following data is the result of the writer's test about this point, by germinating such pollens on the bed of 10 per cent cane sugar solution.

Table 2-Percentage of germinated pollens

\begin{tabular}{c|c}
\hline $\begin{array}{c}\text { Pollens left in the bag for } 24 \text { hours after the breaking- } \\
\text { up of anther }\end{array}$ & $25.9 \%$ \\
\hline $\begin{array}{c}\text { Pollens gathered soon after the breaking-up of anther and } \\
\text { stored in a desiccator for } 24 \text { hours }\end{array}$ & $88.5 \%$ \\
\hline
\end{tabular}

The treatment of pollination was carried out from $7: 30$ a.m. to 9 a.m.. To know the effect of this operation, the percentage of fruit setting was examined on the 15th of May, when fruits were thinned, only one in each cluster being left. At the same time, the average weight of the fruit thinned out of each experimental section was measured to compare the degree of fruit development at its earlier stage. 
Kobayashi, A Few Factors Associated with the Growth of Pear Fruit

The climatic conditions during the period of pollination were as fo'lows:

Table 3-The climatic conditions during the period of polinnation

\begin{tabular}{c|c|c|l|l}
\hline \hline & $\begin{array}{c}\text { Temperature } \\
\text { at 10 a.m. }\end{array}$ & $\begin{array}{c}\text { Relative humi- } \\
\text { dity at 10 a.m. }\end{array}$ & $\begin{array}{c}\text { Weather } \\
\text { condition }\end{array}$ & Wind velocity \\
\cline { 2 - 5 } April 21 & $16.7^{\circ} \mathrm{C}$ & 81 & fair & mean \\
22 & 14.8 & 98 & rain & mean \\
23 & 13.7 & 77 & fair & mean \\
24 & 11.3 & 89 & cloudy & mean \\
25 & 20.3 & 92 & rain in after- & strong \\
26 & 13.4 & 89 & noon & fair \\
\hline
\end{tabular}

\section{RESULTS}

1. Age of pistils in relation to set of fruit and its growth

It has been observed to be one of the most important characteristics for the pollinizer to blossom at the same time as, or rather at an earlier time than the main variety in orchard.

If, however, the receptivity of pistils would continue for a longer period after the opening of blossoms, it might be better to select for the pollinizer such a variety as of higher compatibility and of higher market value. $\mathrm{Or}$, when the date of pollination is a little delayed after the opening of

Table 4-Age of pistils in Relation to fruit setting

\begin{tabular}{c|c|c|c|c|c|c}
$\begin{array}{c}\text { Age of } \\
\text { pistils }\end{array}$ & $\begin{array}{c}\text { Date of } \\
\text { pollination }\end{array}$ & $\begin{array}{c}\text { Number of } \\
\text { blossoms }\end{array}$ & $\begin{array}{c}\text { Number } \\
\text { of set } \\
\text { fruit }\end{array}$ & $\begin{array}{c}\text { Average } \\
\text { Set- } \\
\text { percentage }\end{array}$ & $\begin{array}{c}\text { weight of } \\
\text { fruit at the } \\
\text { time of } \\
\text { thinning }\end{array}$ & $\begin{array}{c}\text { Average } \\
\text { weight } \\
\text { of mature } \\
\text { fruit }\end{array}$ \\
\hline 1 & April 21 & $123((41))$ & 116 & 94.43 & $0.99(75)$ & $310(20)$ \\
2 & 21 & $108((36))$ & 102 & 94.44 & $0.99(66)$ & $285(18)$ \\
3 & 23 & $141((47)$ & 125 & 88.6 & $0.94(75)$ & $320(18)$ \\
3 & 24 & $132((44))$ & 116 & 87.9 & $0.88(68)$ & $330(21)$ \\
4 & 24 & $105((35))$ & 63 & 60.4 & $0.63(20)$ & $275(14)$ \\
5 & 25 & $132((44))$ & 30 & 22.5 & $0.50(14)$ & $250(5)$ \\
6 & 26 & $141((47))$ & 22 & 15.4 & $0.44(16)$ & $185(5)$ \\
Standard & & $159((53))$ & 82 & 51.3 & $0.42(25)$ & $2 \varepsilon 5(16)$ \\
\hline
\end{tabular}

Remarks:

1. Standard section was left to open-pollination with the blossoms open on April 21.

2. Figures in double parenthesis indicate number of clusters employed.

3. Figures in simple parenthesis indicate number of fruit measured.

blossoms, owing to the unfavorable weather which prevents insects from calling the blossoms, what effects would be witnessed on the percentage of fruit setting and on the growth of fruit?

To solve these questions, the experiment was conducted by crossing the 
pistils of different ages of Yari with the pollens of Tsuri, though this cross was reve:se in usual cases on account of the number of the trees. The following table (4) and figure (1) represent the result of it:

Thus, it has been seen that when the pollination was delayed after the opening of blossoms, the receptivity of the pistils gradually decreased with the lapse of time. In fact, when pollinated, the stigmas of the pistils of five or six days old were observed somewhat discoloured and dried, secreting less stigmal fluid. Generally stating, the pistil seams to have receptivity of some industrial value only for three or four days after the open:ng of the blossoms. But, it must be borne in the mind that the climatic conditions much affect the receptivity as it will be described in a later clause.

With regard to the effect of the age of pistils upon the growth of fruit, it is observable that there exists

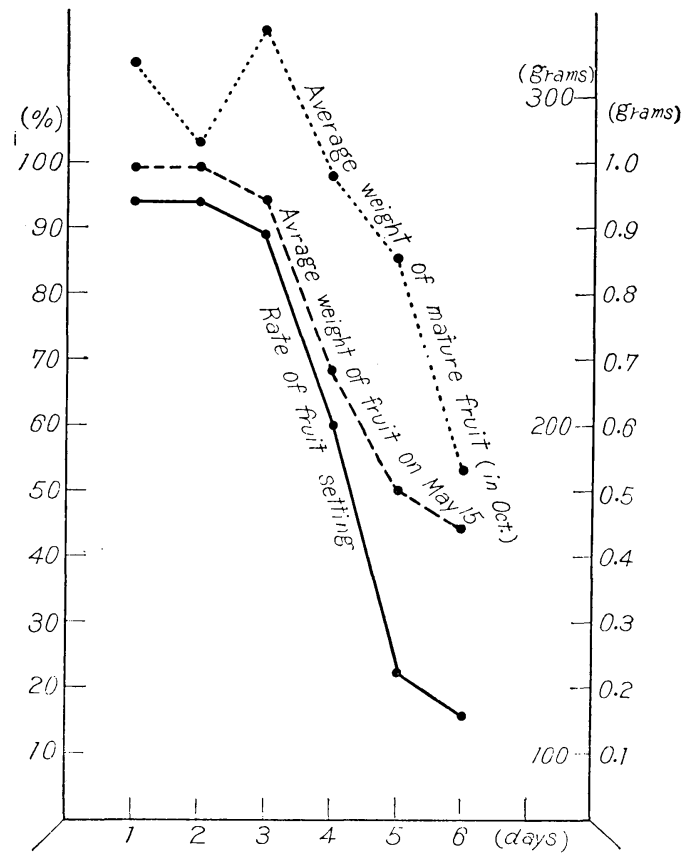

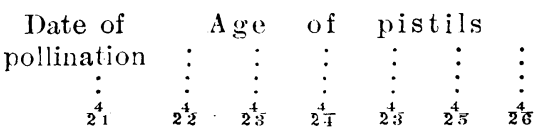

FIG. 1. Age of pistils in relation to fruit setting in it something interesting, as for instance the pistils of 3 days old specified $87.9 \%$ set fruit, 0.88 grams in the average weight of fruit at the time of thinning (May 15) and 330 grams in the average weight of mature fruit (in October), while those of 4 days old recorded respectively $60.4 \%$, 0.68 grams and 275 grams, though the both were pollinated on the same day, i.e. on April 24. This accounts for the fact that the younger the age of pistills after the opening of blossoms, the higher and greater the rate of set fruit and its growth in weight. (The point will be refered to in detail in the chapter IV.)

As to the fact that such a low rate of fruit setting as $51.3 \%$ was recorded in the standard section which was left to open-pollination with the blossoms open on April 21, two or three reasons can be given as below.

First, it is less calling of pollen-carrying insects, chiefly due to the low 
temperature which delayed the pollination at least two or three days as compared with the sections artificially pollinated. The second is that in such an orchard where many trees of different varieties grow together, the k.nd of pollens carried to a stigma by insects is decided by chance as quite different from the artificial pollination, from both varietal and pollen-aged standpoint. So there are much possibilities, in this cese, of crossing with the pollens which may bring about the low rate of set as already specified. Thirdly, when discussing only about the rate of fruit setting and weight of fruit at the time of thinning, the effect of not bagging in and after the blossoming period in the standard section, as for instance recording a low temperature of fruit, ray be considered as one of the main causes of the above results.

2. Date of pollination in relation to growth of fruit.

In the case of the Chinese pear, as it takes 3 or 4 ciays for all the flower buds of one variety to open even presuming each of them pollinated soon after its opening, there ought to be difference in the date of pollination. Consequently this affects in some way the growth of fruit.

To make this fact clca:", the experiment was carrid out for six days, by crossing the pistils of Yari with the pollens of Tsuri just on the flowering day. The result is as follows:

Table 5-Date of pollination in Relation to growti of fruit

\begin{tabular}{|c|c|c|c|c|c|}
\hline $\begin{array}{l}\text { Date of } \\
\text { pollination }\end{array}$ & $\begin{array}{c}\text { Number of } \\
\text { blossoms } \\
\text { pollinated }\end{array}$ & $\begin{array}{l}\text { Number of } \\
\text { set fruit }\end{array}$ & $\begin{array}{c}\text { Set- } \\
\text { percentage }\end{array}$ & $\begin{array}{l}\text { Average } \\
\text { weight of fruit } \\
\text { at the time } \\
\text { of thinning }\end{array}$ & $\begin{array}{l}\text { Average } \\
\text { weight of } \\
\text { mature fruit }\end{array}$ \\
\hline April 21 & $123 \quad((41))$ & 116 & 94.4 & $0.99(75)$ & $310 \stackrel{\text { grams }}{(20)}$ \\
\hline 23 & $105 \quad((35))$ & 90 & 90.1 & $0.95 \quad(55)$ & $325 \quad(18)$ \\
\hline 24 & $99 \quad((33))$ & 95 & 96.2 & $0.89(62)$ & $326 \quad(14)$ \\
\hline 25 & $111 \quad((87))$ & 83 & 75.0 & 075 (44) & 280 (11) \\
\hline 20 & $81 \quad((27))$ & 77 & 94.5 & $0.77(50)$ & 310 (14) \\
\hline
\end{tabular}

Remarlis:

1. Figures in double parenthesis indicate number of clusters employed.

2. Figures in simple parenthesis indicate number of fruit investigated.

As Table 5 and Fig. 2 illustrate, the blossoms pollinated on the day of the opening showed above 90 per cent set fruit except those on April 25, thus indorsing the statement already made that the receptivity of pistils is the highest in the rate of fruit setting on the day of blossom-opening. The depression of the set-percentage on April 25 is accountalle for the unfavorable weather condition recorded on the day.

Concerning the weight of fruit at the time of thinning (May 15), it seems somewhat to be correlated with the date of pollination, namely, the earlier the date of pollination, the heavier the weight, as evidently shown in Fig. 2. This also agrees with the fact in the pear tree, the fruits at basal part of esch cluster precede both in we'ght and maturity to those at upper 
part, because the blossoms in each cluste $i$ beyin to open at the base. Besides, it is noticeable that the blossoms pollinated on April 25 showed exceptionally the lower value than those on April 26, not only in the rate of fruit satting but also in the average weight of fruit, as if there exists some correlation betwean thase.

About the reation between the date of pollination and the average weight of mature fruit, it was impracticable to reach a definite

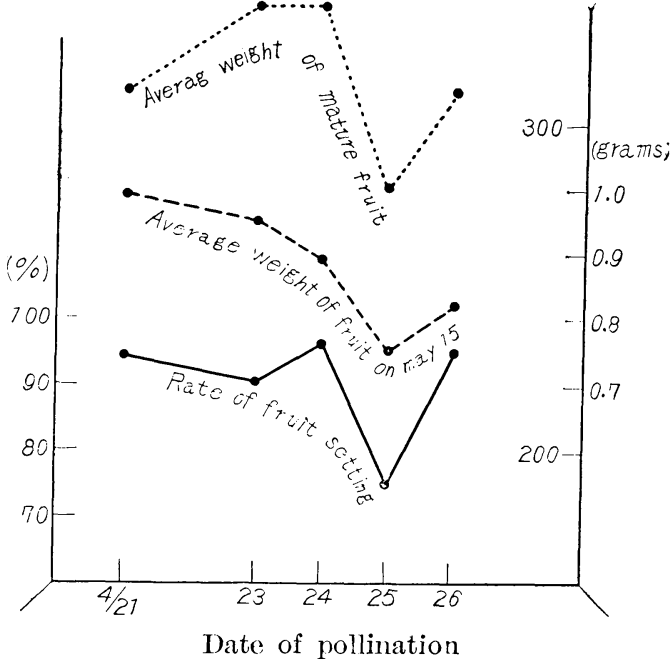

FIG. 2. Date of pollination in relation to growth of fruit in weight conclusion, as the number of fruit tested for the purpose in each experimental section was too small to compare adequately.

3. Variety of pollens in relation to set of fruit and its growth.

There are many reports approving the theory of metaxenia rhenomenon, but if elosely examined, it might be found that most of them have drawn conclusions hy ignoring the difference in fruit development which relates to such simple facts as the difference in the date of pollination or that in the rate of fruit setting, in polloination, as already referred to. The writer of this paper with this point in view intends to study further this phenomenon in futuie.

Again, of late, as the planting of Chinese pears (chiefly T'suri) has much increased in this prefecture, it is necessary to select proper pollinizer's for the enterprise.

For the purposes above mentioned, the experiment was performed by crossing Tsuri with Imamuraaki, Yari, Nijisseiki, Kikusui and Yakumo, with the result described below:

TABLE 6-VARIETIES OF POLLEN IN REIATION TO FRUIT SETTING AND ITS GROWTH

\begin{tabular}{|c|c|c|c|c|c|}
\hline Cross & $\begin{array}{l}\text { Date of } \\
\text { crossing }\end{array}$ & $\begin{array}{c}\text { Number of } \\
\text { b'ossoms }\end{array}$ & $\begin{array}{l}\text { Number of } \\
\text { set fruit }\end{array}$ & $\begin{array}{c}\text { Set- } \\
\text { percentage }\end{array}$ & $\begin{array}{c}\text { Average } \\
\text { weight of } \\
\text { mature fruit }\end{array}$ \\
\hline \multirow{6}{*}{ 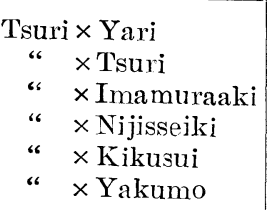 } & April 21 & $57 \quad(19)$ & $\begin{array}{l}\% \\
53\end{array}$ & 93.6 & $440 \stackrel{\text { grams }}{(8)}$ \\
\hline & 23 & 117 (39) & 0 & 0.0 & - \\
\hline & 23 & $93 \quad(31)$ & 62 & 663 & $380 \quad(13)$ \\
\hline & 24 & $105 \quad(35)$ & 55 & 52.2 & $385 \quad(10)$ \\
\hline & 27 & $48 \quad(16)$ & 3 & 6.3 & $290(2)$ \\
\hline & 27 & $75 \quad(25)$ & 44 & 58.6 & $362 \quad(8)$ \\
\hline
\end{tabular}

Remark: Figures in parenthesis indicate number of clusters employed. 
Thus T'suri can be said as of self-incompatibility, requiring therefor som? pollinizers for which Yari is, as it has been so believed, the mcst ideal one when taking in consideration its blossoming period and compatibility with T'suri.

In this experiment, it is regrettable that the weight of fruit at the time of thinning were not measured; moreover, though the average weight of mature fruit in each cross was taken, it can not be made an object of comparison in this connection as the number of fruit investigated was too small.

However, it is worthy of consideration that the erossing between Tsuri and Kikusui was the lowest in the set-percentage, and so was in the weight of mature fruit, a fact which allows supposition that the stakility of compatibility is presumably associated with the growth of fiuit enphatically when it lowers below a certain level.

\section{DISCUSSION}

The writer is of opinion that the percentage of fruit setting in pollination signifies not only an index of total functions of various factors which govern the fruit setting in and after the time of pollination but also a fact that the same percentage is, in a way, in a close connection with some internal factors which control the rate of growth of fruit or its vital force, at least at an earlier stage of fruit development.

With this point in view, he extracted some material respectively from Table 4 and Table 5 to compare the two groups with respect to the degree of fruit development in weight that were pollinated on the same day, but were of diff srant set-percentage. The result is shown as follows:

Table 7 -Set-percentage in reiation to fruit Development in Weight, TAKING TIE DATE OF POLLINATION INTO ACCOUN'T

\begin{tabular}{|c|c|c|c|c|c|c|}
\hline \multirow[b]{2}{*}{$\begin{array}{c}\text { Date of } \\
\text { polli- } \\
\text { nation }\end{array}$} & \multicolumn{2}{|c|}{$\begin{array}{c}\text { Group I } \\
\text { Extracted from Table } 4\end{array}$} & \multicolumn{2}{|c|}{$\begin{array}{l}\text { Group II } \\
\text { Extracted from Table } 5\end{array}$} & \multicolumn{2}{|c|}{$\mathrm{II}-\mathrm{I}$} \\
\hline & $\begin{array}{c}\text { Set- } \\
\text { percentage }\end{array}$ & $\begin{array}{l}\text { Average } \\
\text { weight of } \\
\text { fruit on } \\
\text { May } 15\end{array}$ & $\begin{array}{c}\text { Set- } \\
\text { percentage }\end{array}$ & $\begin{array}{c}\text { Average } \\
\text { weight of } \\
\text { fruit on } \\
\text { May } 15\end{array}$ & $\begin{array}{c}\text { Difference } \\
\text { in set- } \\
\text { pescentage }\end{array}$ & $\begin{array}{c}\text { Dif- } \\
\text { ference } \\
\text { in weight } \\
\text { of fruit }\end{array}$ \\
\hline April 21 & $9 \stackrel{\%}{1 \% 4}$ & $\begin{array}{l}\text { grams } \\
0.99\end{array}$ & $\begin{array}{c}\% \\
94.43\end{array}$ & $\begin{array}{l}\text { grams } \\
0.99\end{array}$ & $\begin{array}{c}0 . / 6 \\
-0.01\end{array}$ & $\begin{array}{l}\text { grams } \\
0.00\end{array}$ \\
\hline 23 & $\varepsilon 8.6$ & 0.94 & 90.1 & 0.95 & 1.5 & 0.10 \\
\hline 24 & 60.4 & 0.68 & 96.2 & 0.89 & 35.8 & 0.21 \\
\hline 25 & 225 & 0.50 & 75.0 & 0.75 & 52.5 & 0.25 \\
\hline 26 & 154 & 0.44 & 94.5 & 0.77 & 79.1 & 0.33 \\
\hline
\end{tabular}

As evident from Table 7 and Fig. 3, when the date of pollination is the same, the cross of the lower set-percentage is always in inferior in the average we'ght of fruit, and the larger the lowering in the sat-percentage, 
the greater the decrease in the average weight of fruit, suggesting theraby the existence of some positive correlation between set-percentage and fruit development.

Besides, in comparing the fruit in Group I, as pollinated on April 24, with that in Group II, as pollinated on April 26, it will be seen that the lowering of the set-percentage is in a closer connection with the fruit development in weight then delay in the date of pollination.

After all, as fir as the present experiment is concerned, it will be concluded that the difference in the date of pollination caused the difference in the growth of fruit due to the different length of the growing period or its sequent sliding, while the difference in the set-percentege related to the growth of fruit through the difference in the rate of glowth or that in the vitality of fruit.

However, this relation of set-pereentage in the pollination to the growth of fruit could not necessarily be applied to every case, because

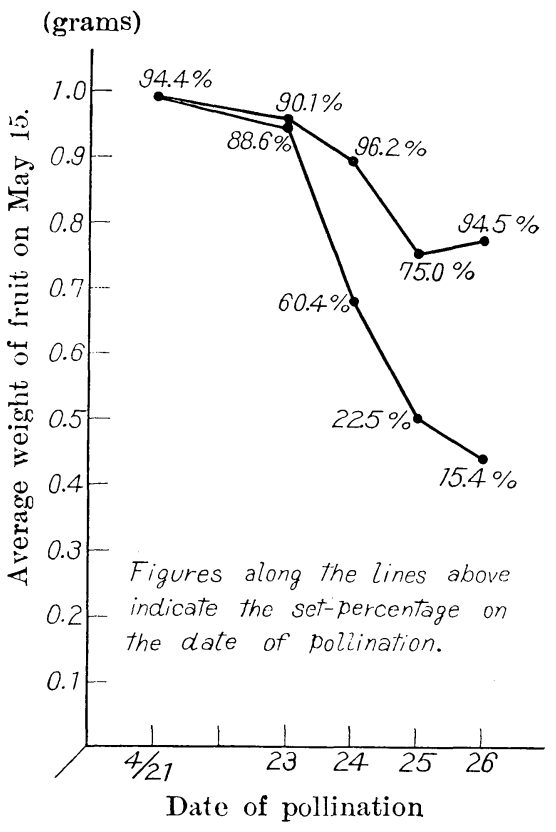

Fig. 3. Set-percentage in relation to fruit development taking the date of pollination into account in addition to age of pistils, there are many other different causes which govern the rate of fruit setting, either phisiologically or genetically; externally or internally.

Regarding this point, there exists another interesting fact-already described in the last clause-that the set-percentage, in the case of the crossing of Tsuri with many other different varieties, seemed to be plainly correlated with some limiting factor of the fruit development in weight only when it lowers below a certain level.

Therefore, it should be desirable to examine this subject in every case further and more extensively, even by investigating the number of seeds contained in a piece of fruit.

\section{CONCLUSIONS AND SUMMARY}

Now, the writer intends to conclude the above mentioned results from the standpoint of selecting the pollinizer for the Chinese pear.

1. It has been known that (i) when pollination are delayed after the opening of bloss.ms the receptivity of pistils decreases gradually with the lapse of time, and (ii) the delay in the date of pollination also brings 
about the delay in the growth of fruit at its earlier stage.

These facts mean that in the case of the Chinese pear, the blossoming period of the pollinizer should be close to that of the main variety in orchard as much as possible.

Needless to say, it is not yet quite clear to what extent the fruit development in its earlier stage would affect its development in maturity, as the number of fruit investigated is not sufficient for the purpose.

2. In the case of the crossing of Yari with the pistils of different age of Tsuri, the lowering of the set-percentage is in a eloser connection with the fruit development in weight than the delay in the date of pollination, that is, while the former relates to the rate of growth or vital force of fruit, the latter only means the shortening or sequent sliding of the growing period.

This would suggest us that the stability of compatibility of the pollinizer with the main variety in orchard relates not only to the percentage of fruit setting, but also presumably to the rate of growth of fruit. In fact, as a result of the experiment refered to, such a fact above given was witnessed plainly though it was only when the set-percentage (the stability of compatibility) lowered below a certain level.

Thus, it will be claimed that the greater the stability of compatibity, the richer and greater the fruit-setting and fruit-development.

3. After all, of the characteristics of the pollinizer, two-i.e. to blossom at the same time as the main variety in orchard as much as possible, and to be of high compatibility with it--are the most important, in the Chinese prar, from the viewpoint of fruit production. Consequently Yari would be said to be the best pollinizer for Tsuri as far as this experiment is concerned.

\section{LITERATURE CITED}

(1) AsAMI, Y: Interpretation of fundamental questions in pomology. (in Japanese) Agr. and Hort. Vol. IX, No. 1-Vol. X, No 12. 1934-1935.

(2) Kinuciri, A.: Conception on the pollination of fruit trees. (in Japanese). Agr. and Hort. Vol. VIII, No. 1-2. 1933.

(3) Terami, H: Histological, physiological and genetical studies of self- and cross-sterility in the japanese pear. Studies from the Inst. of Hort. Kyoto Imp. Univ. Vol. II 1937. 